\title{
Maternal Age and Maternal Environment Affect Egg Composition, Yolk Testosterone, Offspring Growth and Behaviour in Laying Hens
}

Tina M. Widowski ( $\nabla$ twidowsk@uoguelph.ca )

University of Guelph

Leanne Cooley

L.H. Gray \& Son Limited

\section{Simone Hendriksen}

Wageningen University

Mariana R.L.V. Peixoto

University of Guelph

\section{Research Article}

Keywords: Maternal age, maternal environment, egg composition, yolk testosterone, offspring growth, laying hens, cages, maternal effects

Posted Date: July 15th, 2021

DOI: https://doi.org/10.21203/rs.3.rs-708441/v1

License: (c) (i) This work is licensed under a Creative Commons Attribution 4.0 International License.

Read Full License

Version of Record: A version of this preprint was published at Scientific Reports on February 3rd, 2022. See the published version at https://doi.org/10.1038/s41598-022-05491-6. 


\section{Abstract}

Maternal effects have been reported to alter offspring phenotype in laying hens. In this study, we investigated the effects of maternal environment and maternal age on egg traits and offspring development and behaviour. For this, we ran two experiments. First (E1), commercial hybrid hens were reared either in aviary or barren brooding cages, then housed in aviary, conventional cages or furnished (enriched) cages, thus forming different maternal housing treatments. Hens from each treatment were inseminated at three ages, and measures of egg composition, yolk testosterone concentration and offspring's development, anxiety and fearfulness were assessed. In experiment 2 (E2), maternal age effects on offspring's growth and behaviour were further investigated using fertile eggs from commercial breeder flocks at three ages. Results from E1 showed that maternal age affected the majority of measures including egg composition, yolk testosterone, offspring growth, anxiety and fearfulness. Maternal rearing and housing affected fewer measures but included egg characteristics, offspring weight and behaviour. Effects of maternal age were not replicated in E2, possibly due to higher tolerance to maternal effects in commercial breeders. Overall, our research confirms that maternal environment and maternal age affect the offspring of laying hens in a variety of ways. These effects may be mediated by the natural decrease in egg yolk testosterone concentration over time.

\section{Introduction}

In egg production systems, all laying hens are descendants of layer breeder flocks. The breeder hen's life experience, whether positive or negative, can affect the behaviour and stress susceptibility of laying hens through epigenetic effects ${ }^{1-3}$ or changes in the concentration of hormones and nutrients deposited by the mother in her eggs ${ }^{4,5}$. Over the years, research in layer breeders has resulted in advances in management, nutrition and genetics; however, there is a paucity of literature regarding the mechanisms, causes and consequences of maternal effects for this group of birds. Given that the global population of commercial layers is 7.6 billion animals, and each layer breeder produces approximately 115 offspring ${ }^{6}$, maternal effects in layer breeders can potentially affect innumerous hens around the world.

The phenotype of the laying hen is primarily determined by the combination of her genotype, environment and early-life history. In addition, environmental stressors experienced by the mother can affect her offspring. In the egg industry, the term "environment" comprises a series of aspects that include the type of rearing and housing systems, population density and husbandry that the birds are subjected to, from hatch to slaughter. Studies on commercial hens have consistently linked housing environment with shortand long-term effects on physical and cognitive traits. For example, hens reared in aviary showed improved bone and muscle growth ${ }^{7,8}$, better use of space ${ }^{9,10}$ and reduced fearfulness ${ }^{11}$ and stress response ${ }^{12}$ in comparison to birds reared in conventional brooding cages. Similarly, adult housing was shown to affect behaviour and stress response, with hens reared in conventional cages and housed in furnished cages being less stressed than hens both reared and raised in conventional systems ${ }^{13,14}$. Recently, offspring effects related to maternal rearing and housing condition have also started to be reported. A multifactorial analysis of laying production, production of hatching eggs, and the number of 
waste eggs showed that layer breeders reared in aviary and housed on litter had better results compared to cage-reared birds ${ }^{15}$. Additionally, our research group reported that maternal environment affected offspring's social behaviour and stress response, with aviary-reared mothers having less emotional offspring, whereas aviary-housed mothers had chicks with a lower stress response ${ }^{16}$.

Changes in the concentration of egg hormones and nutrients have been suggested as mediators for maternal effects in oviparous species ${ }^{4,5}$. Research has shown that maternal experiences can lead to changes in egg composition that, in turn, might affect offspring phenotype ${ }^{5}$. Hens subjected to a moderate heat challenge for five consecutive weeks laid eggs with higher concentrations of yolk steroid hormones (progesterone, testosterone and estradiol) and had lighter and calmer offspring than the control group ${ }^{17}$. Similarly, in the Japanese quail, mothers subjected to stressful events, such as sudden movement or unpredictable noise, laid eggs with higher yolk testosterone and progesterone, and produced chicks more sensitive to social separation (i.e., vocalized more during emergence and open-field tests) ${ }^{18}$. Androgen hormones such as testosterone have been suggested to be the main mediator of maternal effects in poultry species ${ }^{19}$; however, other egg components have also been investigated (glucocorticoid hormones ${ }^{20}$, thyroid hormones ${ }^{21,22}$, antioxidants ${ }^{23}$ and immunoglobulins ${ }^{24}$ ).

Another potential source of maternal effects in laying hens is maternal age. As a hen gets older, the size and quantity of solid content in her eggs naturally increase ${ }^{25}$. In addition, yolk testosterone concentration may decrease over time, such as seen in the Japanese quail 26,27 . Ageing has also been linked to changes in yolk fatty acid profile ${ }^{28,29}$ and late embryonic mortality, hatchability, and body weight in the offspring of broiler breeders ${ }^{30}$. Although the current study is the first of its kind to assess how ageing affects yolk testosterone concentration in laying hens, a previous publications from our research group reported that maternal age increased both the endocrine and behavioural response of the offspring to manual restraint and affected different aspects of injurious social behaviour in laying hens ${ }^{16}$. Layer breeder flocks typically start producing offspring at around 20 weeks of age and remain in production until around 70 weeks of age, reaching an optimized performance at approximately 44 weeks ${ }^{31,32}$. Therefore, layer breeder's age may also be a source of maternal effects in the offspring.

The current study is part of a more comprehensive research project on maternal effects ${ }^{16,33-35}$ that aim at investigating how maternal age, maternal rearing experience and maternal adult housing system affect their offspring's behaviour and stress response. For this, we conducted two experiments. In the first (E1), two cohorts of commercial hybrid (Lohmann Selected Leghorn -Lite) hens were reared and housed in five housing system combinations and were inseminated at three ages $(25,44$ and 68 woa), producing six offspring flocks. Measurements of egg composition, yolk testosterone concentration, and offspring growth and behaviour were assessed. To test the replicability of any maternal age effects found in E1 in commercial breeder flocks (parent stock), we conducted a second experiment (E2) in which hatching eggs from layer breeders at three age groups ("Young" (25-27 woa), "Ideal" (42-46 woa) and "Old" (68-72 woa)) were obtained from various commercial flocks across Canada and the United States. Data collection 
included measures of body weight and behaviour. We hypothesized that maternal effects related to age and environment would be found in E1 and predicted the replicability of maternal age effects in E2.

\section{Methods}

This study was carried out in compliance with the ARRIVE guidelines and birds were treated in accordance with the Canadian Council on Animal Care. All procedures were approved by the University of Guelph Animal Care Committee (Animal Utilization Protocol \#1947).

\section{Experiment 1 (E1)}

\section{Parent stock}

The methodology of this experiment has been described in further detail in Peixoto et al. ${ }^{16}$. In short, two consecutive cohorts of 778 Lohmann Selected Leghorn Lite (LSL-Lite) pullets each, were obtained from a commercial hatchery at one day of age and transferred to the University of Guelph's Arkell Poultry Research Station. Immediately upon arrival, half of the pullets from each flock were housed in conventional brooding cages $(C C, n=408)$, while the other half was assigned to a tiered pullet aviary ( $A v$, $\mathrm{n}=370$ ) system. At 16 weeks of age, pullets from Av rearing were transferred to conventional cages (CC; $\mathrm{N}=12$ cages of 8 hens), furnished cages ( $F C ; N=12$ cages of 60 hens) and aviary systems ( $A v ; N=2$ aviary groups of 370 hens). Pullets from CC rearing were transferred to $C C(N=12$ cages of 8 hens) or $F C(N=12$ cages of 60 hens).

Each rearing and housing combination was considered a treatment (Figure 1). A sample of 96 hens from each treatment were randomly selected and inseminated with pooled semen from a contemporary group of White Leghorn males at 3 ages: Young (25 weeks), Ideal (44 weeks) and Old (68 weeks). Eggs from each maternal age, treatment and flock were collected and stored at $4^{\circ} \mathrm{C}$ until incubation.

\section{Egg composition and yolk testosterone concentration}

A subset of eggs from each treatment and cohort were collected two days prior to each insemination and subsequently analyzed for egg quality traits $(N=1444)$ and yolk testosterone $(N=441)$. Eggs were weighed, broken, and the yolks were separated from the albumen. Before weighing, the chalazae were removed with a forceps and all yolks were rolled on a paper towel to remove adhering albumen. The shells were carefully washed and dried for $48 \mathrm{~h}$ in a drying oven at $21 \mathrm{C}$ and then weighed. Albumen weight was determined by subtracting yolk and shell weight from the original egg weight.

Testosterone concentration in yolk was analysed via enzyme immunoassay (EIA; antibody against testosterone-3-CMO), and followed an adapted methodology from Henriksen et al ${ }^{36}$. Egg yolks were homogenized to ensure adequate mixing of hormones from different regions of the yolk sphere. Samples were extracted by mixing $0.15 \mathrm{~g}$ of yolk with $0.6 \mathrm{ml}$ of double-distilled water and $3 \mathrm{ml}$ of methanol were added. Solution was homogenized with a vortex placed in a walk-in cold room at $2 \mathrm{C}$ overnight. On the next day, solution was placed in $-20 \mathrm{C}$ freezer for $2 \mathrm{~h}$ to precipitate apolar lipids, that were transferred into 
a new vial. The remaining solution was centrifuged at $2500 \mathrm{~g}$ for 15 minutes at $4 \mathrm{C}$ and stored in aliquots of $2 \mathrm{ml}$. The minimum detectable hormone level was $0.59 \mathrm{ng}$ per gram of yolk.

\section{Offspring management and data collection}

Offspring were incubated and hatched at the University of Guelph's Arkell Poultry Research Station. Chicks were sexed and individually wing-banded at hatch. Each cohort had four replicate groups of progeny (7 males and 7 females/each) per treatment and maternal age $(N=1,680)$. Replicates were identically reared to 15 weeks in 20 floor pens $\left(3.72 \mathrm{~m}^{2}\right.$ ) that had a perch (length: $155 \mathrm{~cm}$ ) and were bedded with litter. Offspring were weighed at hatch and 91 days of age. Behavioural tests were performed as described below. The test order for each test was balanced across treatment and time of day in order to minimize effects of circadian rhythm on results.

\section{Social isolation test}

The social separation of young chicks from their conspecifics produces an increase in distress vocalizations ${ }^{37}$, allowing for measurement of anxiety-related behaviours. Following the methodology proposed by Sufka et al. ${ }^{38}$, chicks at $5-6$ and $32-33$ days of age $(N=960)$ were individually placed into a sound-proof box ( $63.5 \mathrm{~cm}$ high X $63.5 \mathrm{~cm}$ deep X $63.5 \mathrm{~cm}$ wide) where their vocalizations were recorded (for pictures of the box and further details on methods, please see Peixoto et al ${ }^{34}$ ). Each chick was tested at one age only. The test lasted 5 minutes and was conducted from 08:00 to 12:00 h and from 14:00 to 18:00 $\mathrm{h}$ in a quiet room close to their home pen. Total distress vocalizations (TDV) were recorded, saved as a MPEG-4 file using the Voice Memos application (Apple, Cupertino, USA). One observer blind to treatment used WavePad (NCH Software, Greenwood Village, USA) to count and record TDV.

\section{Novel object test}

The novel object test measures the conflicting motivation to approach or avoid a potentially dangerous stimulus and it has been traditionally used as an indicator of fear ${ }^{39}$. Following the methodology proposed by de Haas ${ }^{40}$ and based on the Welfare Quality assessment ${ }^{41}$, the novel object test was conducted at 3, 5 and 10 weeks of age. Each group of progeny ( $N=60$ pens with 14 birds / each) was exposed to a wooden box $(5 \times 5 \times 2 \mathrm{~cm})$ covered with coloured tape (green, yellow, red and white) in a striped pattern. The novel object was placed on the floor inside the birds' home pen. A camcorder (Panasonic HC-V180K) was suspended from the ceiling, providing a complete overhead view of the pen. Behaviours were analyzed every $10 \mathrm{~s}$ by one observer blind to treatment. Data collection included the time points at which at least three birds were in close proximity of the object (one bird length: $<25 \mathrm{~cm}$ and two bird length : $<50 \mathrm{~cm}$ ) and were observed to touch/peck the object; which we used as the latencies to approach and peck. 


\section{Tonic immobility test}

The Tonic Immobility ( $\mathrm{TI}$ ) methodology initially proposed by Jones ${ }^{42}$ and previously described by Peixoto et al ${ }^{33}$ was used to measure fearfulness. At 9 weeks of age, 2 males and 2 females from each replicate group ( $\mathrm{N}=480)$ were individually caught, moved into a quiet nearby pen and placed on their back in a Vshaped cradle, where the experimenter gently applied pressure on their sternum. If birds became immobile for a minimum of 10 seconds, it was considered a successful induction. If not, up to 5 consecutive attempts to induce TI were performed. Each test lasted 10 minutes, or until the bird stood up. Testing was recorded using a camcorder (Panasonic HC-V180K) positioned perpendicularly to the cradle. The camera was plugged to a monitor located out of the birds' sight in order to reduce effect of experimenter on the bird. Behaviours were analyzed from videos by one trained observer blind to treatment. Data collection included latency to look around, latency to stand up, number of vocalizations emitted during the test and number of attempts needed to attain a successful induction.

\section{Experiment 2 (E2)}

\section{Parent stock, offspring management and data collection}

In our second experiment, we aimed to further investigate the effects of maternal age in layer breeders obtained from commercial settings. For this, fertile eggs were acquired from 9 unique, commercial LSLLite White Leghorn layer breeder flocks located in Ontario, Quebec and New Brunswick, Canada and from Pennsylvania, USA. Breeder flocks were loose-reared and housed in floor barns. At the time of egg collection, 3 of the flocks were Young (25-27 woa), 3 were Ideal (42-46 woa) and 3 were Old (68-72 woa). All of the fertile eggs were shipped to University of Guelph's Arkell Poultry Research Station within the same week where egg storage, incubation and hatch occurred together, following the procedures previously described. From each parent flock, 2 replicates of progeny ( 7 males and 7 females; $n=28$ per flock; 3 flocks/age; $\mathrm{N}=252$ ) were identically reared to 42 days of age.

Offspring were subjected to identical husbandry and housing as E1. Data collection included body weight at hatch and 41 days of age $(\mathrm{N}=252)$ and half of the chicks were subjected to a social isolation test at 56 days of age $(\mathrm{N}=126)$ which followed the methodology previously described.

\section{Data analyses}

The Glimmix procedure of SAS 9.4 (SAS Institute, Cary, NC) was used to perform statistical analyses. The basic statistical model for $\mathrm{E} 1$ included fixed effects of sex, maternal treatment (maternal rearing $\mathrm{x}$ adult housing), maternal age, maternal treatment $x$ maternal age, maternal treatment $x$ sex and maternal age $x$ sex. Random effects included cohort, home-pen nested within room and person applying the test when applicable. Contrast comparisons tested effects of maternal rearing (Av or CC) and housing (Av, CC or CF). Data from the social isolation and tonic immobility tests were lognormally transformed to meet the assumption of a normal distribution of residuals. Statistical models accounted for repeated measures 
when applicable. In E2, we used a generalized mixed model to test the effects of sex and maternal age. Random effects included flock of origin and home-pen of the tested bird nested within room. Tests for normality included Shapiro-Wilk and Anderson Darling measurements in conjunction with visual plots for all analyses and statistical significance was defined as $\mathrm{P}<0.05$ for both studies. Unless otherwise indicated, raw means and standard errors are given in the tables and figures.

\section{Results}

\section{Egg composition and yolk testosterone concentration}

Egg composition and yolk testosterone concentration for E1 are presented in Table 1. Results were as expected, with an increase $(P<0.0001)$ in egg weight $(\mathrm{g})$ and yolk $(\%)$ as the hens aged. Hens both reared and housed in aviary systems (Trt 1, AV x AV) produced eggs of different interior composition with less ( $P$ $<0.0001)$ yolk $(\%)$, and more $(P<0.0001)$ albumin $(\%)$ content. A statistical contrast analysis determined that hens who were reared in aviaries produced heavier $(P \leq 0.0442)$ eggs than hens that were conventionally reared.

A significant effect of maternal age on yolk testosterone content showed that Young hens deposited significantly $(P=0.0260)$ more yolk testosterone $(\mathrm{ng} / \mathrm{g}$ yolk) than Old hens. There was no significant effect of either maternal rearing or housing environment on yolk testosterone content. Additionally, there were no interactions between maternal age, or the maternal rearing $x$ adult housing environment. 
Table 1

Egg composition and yolk testosterone concentration. Mean \pm SEM for egg quality traits, egg composition and yolk testosterone of eggs from hens in the Controlled Cohort study collected at three different ages

\section{Experiment 1}

Variable

$\begin{array}{llll}\text { EW } & \text { YW } & \text { AW } & \text { YT } \\ \begin{array}{lll}\text { Egg } \\ \text { Weight }\end{array} & \begin{array}{l}\text { Yolk } \\ \text { Weight }\end{array} & \begin{array}{l}\text { Albumin } \\ \text { Weight }\end{array} & \begin{array}{l}\text { Yolk } \\ \text { Testosterone } \\ \text { (ng) }\end{array}\end{array}$

(g)

$(\%)$

$(\%)$

Overall $P$-value

EW YW AW YT

Maternal

Age

Young

$\begin{array}{llll}56.9 \pm & 24.7 \pm & 63.5 \pm & 1.46 \pm 0.14^{\mathrm{a}} \\ 0.20^{\mathrm{c}} & 0.12^{\mathrm{b}} & 0.15^{\mathrm{a}} & \end{array}$

Ideal

$\begin{array}{llll}61.5 \pm & 28.5 \pm & 59.9 \pm & 1.31 \pm 0.03^{\mathrm{ab}} \\ 0.28^{\mathrm{b}} & 0.15^{\mathrm{a}} & 0.14^{\mathrm{c}} & \end{array}$

Old

$64.2 \pm$

$0.34^{\mathrm{a}}$

$28.4 \pm$

$0.16^{\mathrm{a}}$

$60.35 \pm$

$0.16^{\mathrm{b}}$

Maternal

Treatment

$\begin{array}{lllll}\text { Trt 1 (AV x } & 61.33 & 26.44 & 62.13 \pm & 1.39 \pm 0.07 \\ \text { AV) } & \pm 0.61^{\mathrm{a}} & \pm 0.30^{\mathrm{b}} & 0.29^{\mathrm{a}} & \\ \text { Trt 2 (CC x } & 60.55 & 27.65 & 60.62 \pm & 0.21 \pm 0.17 \\ \text { CC) } & \pm 0.88^{\mathrm{b}} & \pm 0.47^{\mathrm{a}} & 0.40^{\mathrm{b}} & \\ & & & \\ \text { Trt 3 (AV x } & 60.92 & 27.55 & 60.85 \pm & 1.25 \pm 0.19 \\ \text { CC) } & \pm & \pm 0.48^{\mathrm{a}} & 0.41^{\mathrm{b}} & \\ & 0.87^{\mathrm{ab}} & & & \\ \text { Trt 4 (CC x } & 60.31 & 27.66 & 60.94 \pm & 1.34 \pm 0.13 \\ \text { FC) } & \pm 0.73^{\mathrm{b}} & \pm 0.45^{\mathrm{a}} & 0.42^{\mathrm{b}} & \\ & 60.66 & 27.55 & 60.86 \pm & 1.20 \pm 0.08 \\ \text { Trt 5 (AV x } & 60.64^{\mathrm{b}} & \\ \text { FC) } & \pm & & & \\ & 0.71^{\mathrm{ab}} & \pm 0.47^{\mathrm{a}} & 0.44^{\mathrm{b}} & \\ & & & & \end{array}$

\section{Materal}

Age $x$

Maternal

Trt

abc Values within a column for Maternal Age and Maternal Rearing $x$ Adult Housing treatments with different superscripts differ $\mathrm{P}<0.05$

$\begin{array}{llll}< & < & < & = \\ 0.0001 & 0.0001 & 0.0001 & 0.7605\end{array}$




\section{Offspring growth}

Growth and body weight data for progeny from both E1 and E2 are presented in Table 2. In E1, offspring hatch weight increased $(P<0.0001)$ with maternal age; however, the inverse was found for ADG and final bodyweight. When hens were Old, their progeny had slower ADG $(P<0.0032)$ and lower final bodyweight $(P=0.0094)$ at 91 days of age, than the progeny that they produced when they were at Young or Ideal breeder ages. Maternal rearing and adult housing both affected hatch weight; with Trt 2 (CC x CC) progeny having lower $(P \leq 0.0076)$ hatch weights than all other treatments. A statistical contrast analysis determined that there was a significant effect of maternal rearing on hatch weight in the E1, with heavier $(P=0.0409)$ hatch weights from Aviary-reared hens.

The maternal age effect on growth patterns for progeny from E2 study did not match those of progeny from E1. In the second experiment, hatch weight was not affected by maternal age and progeny from young breeder hens had the lowest ADG $(P=0.0068)$ and final body weight at 41 days of age $(P=0.0057)$ compared to those of older breeder hens. 
Table 2

Offspring growth. Means \pm SEM for hatch weight, body weight, and ADG for progeny from Experiments 1 and 2.

\section{Experiment 1}

Variable

\begin{tabular}{lll}
\hline$H W$ & BW & ADG \\
$\begin{array}{l}\text { Hatch Weight } \\
(\mathrm{g})\end{array}$ & $\begin{array}{l}\text { Weight } 91 \mathrm{~d} \\
(\mathrm{~g})\end{array}$ & $\begin{array}{l}\text { Avg Daily Gain } \\
(\mathrm{g})\end{array}$ \\
& & \\
\hline $38.4 \pm 0.09^{\mathrm{c}}$ & $\begin{array}{l}1283.4 \pm \\
25.4^{\mathrm{a}}\end{array}$ & $13.7 \pm 0.28^{\mathrm{a}}$ \\
\hline $39.9 \pm 0.13^{\mathrm{b}}$ & $\begin{array}{l}1275.6 \pm \\
24.5^{\mathrm{ab}}\end{array}$ & $13.6 \pm 0.27^{\mathrm{ab}}$ \\
\hline $41.2 \pm 0.18^{\mathrm{a}}$ & $\begin{array}{l}1257.9 \pm \\
24.7^{\mathrm{b}}\end{array}$ & $13.4 \pm 0.28^{\mathrm{b}}$ \\
\hline
\end{tabular}

Maternal Age

$\begin{array}{lll}< & = & = \\ 0.0001 & 0.0094 & 0.0032\end{array}$

Young

Ideal

Old

old

\section{Maternal}

Treatment

\begin{tabular}{|c|c|c|c|}
\hline Trt $1(\mathrm{AV} \times \mathrm{AV})$ & $40.0 \pm 0.26^{a}$ & $\begin{array}{l}1284.5 \pm \\
32.5\end{array}$ & $13.7 \pm 0.36$ \\
\hline Trt 2 (CC x CC) & $39.2 \pm 0.21^{b}$ & $\begin{array}{l}1260.0 \pm \\
32.6\end{array}$ & $13.4 \pm 0.36$ \\
\hline Trt 3 (AV x CC) & $40.1 \pm 0.26^{a}$ & $\begin{array}{l}1274.4 \pm \\
30.6\end{array}$ & $13.6 \pm 0.36$ \\
\hline Trt 4 (CC x FC) & $39.8 \pm 0.22^{a}$ & $\begin{array}{l}1272.8 \pm \\
32.3\end{array}$ & $13.5 \pm 0.35$ \\
\hline Trt $5(\mathrm{AV} \times \mathrm{FC})$ & $40.1 \pm 0.27^{a}$ & $\begin{array}{l}1269.6 \pm \\
33.2\end{array}$ & $13.5 \pm 0.36$ \\
\hline
\end{tabular}

\section{Sex}

\begin{tabular}{|c|c|c|c|}
\hline Cockerel & $40.1 \pm 0.16^{a}$ & $\begin{array}{l}1486.9 \pm \\
5.3^{a}\end{array}$ & $15.9 \pm 0.06^{a}$ \\
\hline Pullet & $39.6 \pm 0.15^{b}$ & $\begin{array}{l}1057.7 \pm \\
4.6^{b}\end{array}$ & $11.2 \pm 0.05^{b}$ \\
\hline
\end{tabular}

\section{Maternal Age x}

Sex

$\begin{array}{lll}\overline{0} & < & < \\ 0.0046 & 0.0001 & 0.0001\end{array}$

Overall $P$-value

HW BW ADG

$\begin{array}{lll}\overline{0} .0076 & \overline{0} & \overline{0} \\ 0.3970 & 0.4429\end{array}$




\section{Experiment 1}

Materal Age x

Trt

Trt x Sex

$\begin{array}{lll}\overline{=} & = & = \\ 0.0791 & 0.6628 & 0.6732 \\ \overline{0} & \overline{0} & = \\ 0.8059 & 0.4808 & 0.4833\end{array}$

Experiment 2

Variable

BW

ADG

HW

Overall $P$-value

HW

Weight 41d

Hatch Weight

(g)

(g)

Avg Daily Gain

(g)

$\begin{array}{lll}\overline{\overline{0}} & \overline{\bar{N}} & \overline{\overline{ }} \\ 0.3103 & 0.0068 & 0.0057\end{array}$

Maternal Age

Young

$38.6 \pm 0.39$

$440.2 \pm$

$11.7^{\mathrm{a}}$

Ideal

$40.4 \pm 0.55$

$466.3 \pm 14.6^{c}$

$10.4 \pm 0.36^{b}$

Old

$39.8 \pm 0.58$

$456.3 \pm$

$14.3^{\mathrm{b}}$

Sex

Cockerel

$39.7 \pm 0.44$

$39.5 \pm 0.52$

$424.6 \pm 3.1^{b}$

$483.9 \pm 5.5^{\mathrm{a}}$

$10.8 \pm 0.13^{a}$

Pullet

$39.5 \pm 0.52$

\section{Maternal Age x}

Sex

abc Values within a column for Maternal Age and Maternal Rearing $x$ Adult Housing treatments with different superscripts differ $\mathrm{P}<0.05$

\section{Social isolation test}

For E1, when chicks were tested at 5-6 days of age, maternal age had a significant effect on TDV ( $\mathrm{P}<$ $0.0001)$; progeny of Young breeder hens had more TDV than those from Ideal, and Old. Chicks tested at 56 days of age vocalized more during the test than chicks tested at $32-33$ days of age $(P<0.0001)$. There was also an interaction between maternal age $x$ chick age $x \operatorname{sex}(P<0.001)$. When their mothers were Young and Ideal ages, pullets vocalized more during the test than cockerals, but TDV did not differ 
between sexes when their mothers were old (Fig. 2). Due to a loss in test sensitivity at 32, 33 days it was determined that this test is best conducted when chicks are younger.

Mean TDV for E1 progeny from hens in the different maternal treatments at the different maternal ages are illustrated in Fig. 3. There was a significant interaction between Maternal Age by Treatment $(\mathrm{P}<$ 0.0001). Trt 3 ( $A V \times C C$ ) had the highest TDV count at Young and Ideal maternal age. The statistical contrast analysis determined that there was an overall effect $(P=0.0068)$ of maternal rearing on TDV whereby progeny from Conventional reared hens had a lower TDV count than progeny of Aviary-reared hens. There was also an effect of Adult housing, where progeny from hens housed in both Conventional and Furnished housing vocalized more $(P<0.0001)$ than progeny from mothers housed in Aviary.

For E2, a similar trend for maternal age on TDV was observed $(P=0.076)$, although values from chicks in this population were much lower than those from E1. TDV during the 5-minute test were $74.7,60.8$, and 41.7 (+ 8.7 LSmeans and pooled SEM) for progeny of Young, Ideal and Old breeder hens, respectively.

\section{Novel Object Test}

Latency to approach the novel object decreased $(P \leq 0.0395)$ with maternal age of the breeder hens (Table 3). There was no effect of Maternal Rearing $x$ Adult Housing treatment; nor were there any interaction effects with either maternal age or progeny age. Statistical contrasts did not identify any overall effects of either maternal rearing or adult housing. However, offspring age resulted in significant $(P$ $<0.0001)$ differences for all variables measured. At three weeks of age, offspring failed to peck the novel object and had the longest time to approach the novel object. Behavioural response to the novel object decreased with offspring age $(P<0.0001)$. 
Table 3

Novel object test. Means \pm SEM for latency to peck and latency to approach a novel object for progeny from the Controlled Cohort Flocks

\section{Experiment 1}

Variable

\begin{tabular}{|c|c|c|c|c|c|}
\hline \multirow[b]{2}{*}{ P-NO } & \multirow[b]{2}{*}{ O-NO } & \multirow[b]{2}{*}{ T-NO } & \multicolumn{2}{|c|}{ Overall $P$-value } & \multirow[b]{2}{*}{$\mathrm{T}-\mathrm{NO}$} \\
\hline & & & P-NO & O-NO & \\
\hline $\begin{array}{l}\text { Latency } \\
\text { to }\end{array}$ & $\begin{array}{l}\text { Latency to } \\
\text { One }\end{array}$ & $\begin{array}{l}\text { Latency to Two Bird } \\
\text { Lengths }\end{array}$ & & & \\
\hline \multirow[t]{2}{*}{$\begin{array}{l}\text { Peck the } \\
\text { NO }\end{array}$} & $\begin{array}{l}\text { Bird } \\
\text { Length }\end{array}$ & from the NO & & & \\
\hline & $\begin{array}{l}\text { from the } \\
\text { NO }\end{array}$ & & & & \\
\hline
\end{tabular}

Maternal Age

$$
\begin{array}{lll}
\overline{0} & \bar{z} & \overline{=} \\
0.6810 & 0.0097 & 0.0395
\end{array}
$$

Young

$94.0 \pm$

3.4

$49.8 \pm 4.2^{\mathrm{a}} \quad 18.9 \pm 2.4^{\mathrm{a}}$

Ideal

$95.4 \pm$

3.3

$41.9 \pm$

$3.7^{\mathrm{ab}}$

$15.0 \pm 2.0^{\mathrm{ab}}$

Old

$91.3 \pm$

3.4

$38.9 \pm 3.6^{b} \quad 15.0 \pm 2.4^{b}$

Maternal Treatment

$\begin{array}{lll}\overline{0} & \bar{z} & = \\ 0.8391 & 0.9624 & 0.9961\end{array}$

Trt $1(A V \times A V)$

$94.0 \pm \quad 45.0 \pm 4.4 \quad 18.0 \pm 3.4$

4.1

Trt 2 (CC x CC)

$95.6 \pm$

$43.1 \pm 4.8$

$17.0 \pm 3.3$

4.4

Trt $3(\mathrm{AV} \times \mathrm{CC})$

$91.9 \pm$

$41.2 \pm 4.6$

$14.5 \pm 2.2$

4.6

Trt 4 (CC x FC)

$95.6 \pm$

$43.0 \pm 4.9$

$14.2 \pm 2.6$

4.2

Trt $5(\mathrm{AV} \times \mathrm{FC})$

$90.8 \pm$

$45.6 \pm 5.3$

$17.8 \pm 3.1$

4.5

Offspring Age

$\begin{array}{lll}< & < & < \\ 0.0001 & 0.0001 & 0.0001\end{array}$

3 weeks

$120.0 \pm$ $0.0^{\mathrm{a}}$

$94.3 \pm 3.0^{\mathrm{a}}$

$38.4 \pm 3.0^{\mathrm{a}}$

abc Values within a column for Maternal Age and Progeny Age with different superscripts differ $\mathrm{P}<$ 0.05 


\begin{tabular}{|c|c|c|c|c|c|c|}
\hline \multirow[b]{2}{*}{5 weeks } & \multicolumn{6}{|c|}{ Experiment 1} \\
\hline & $\begin{array}{l}100.8 \pm \\
2.8^{\mathrm{b}}\end{array}$ & $23.0 \pm 1.2^{b}$ & $9.1 \pm 0.5^{b}$ & & & \\
\hline 10 weeks & $\begin{array}{l}60.0 \pm \\
3.2^{c}\end{array}$ & $13.3 \pm 1.0^{\mathrm{C}}$ & $1.5 \pm 0.1^{\mathrm{c}}$ & & & \\
\hline Materal Age x Trt & & & & $\begin{array}{l}\overline{\bar{l}} \\
0.1715\end{array}$ & $\begin{array}{l}\overline{\overline{0}} \\
0.1719\end{array}$ & $\begin{array}{l}\overline{\bar{l}} \\
0.0505\end{array}$ \\
\hline $\begin{array}{l}\text { Maternal Age x } \\
\text { Offspring Age }\end{array}$ & & & & $\begin{array}{l}\overline{=} \\
0.5486\end{array}$ & $\begin{array}{l}\overline{=} \\
0.1833\end{array}$ & $\begin{array}{l}= \\
0.8924\end{array}$ \\
\hline Trt x Offspring Age & & & & $\begin{array}{l}\overline{\overline{0}} \\
0.9842\end{array}$ & $\begin{array}{l}\overline{\overline{0}} \\
0.6693\end{array}$ & $\begin{array}{l}\overline{\overline{0}} \\
0.1507\end{array}$ \\
\hline
\end{tabular}

\section{Tonic immobility}

Means \pm SEM for variables measured during TI for E1 progeny are presented in Table 4. Maternal age affected the number of vocalizations during the test, with progeny from Ideal breeder hens vocalizing more $(P=0.0034)$ than progeny from either Young or Old breeder hens. Maternal rearing $x$ adult housing did not affect any of the analyzed measures, but birds from Trt 2 (CC $\times$ CC) and Trt 4 (CC x FC) showed a tendency to take longer to look around $(P=0.0659)$. Overall, pullets were less fearful than males; they needed more attempts to induce $\mathrm{TI}(\mathrm{P}=0.0003)$, vocalized more and showed shorter latency to look around during the test.

Statistical contrasts identified an overall effects of maternal rearing whereby progeny from breeder hens reared in aviaries, as compared to conventional cages, had a shorter $(P=0.0045)$ latency to come out of $\mathrm{TI}$ and look around. 
Table 4

Means \pm SEM for number of attempts to induce, number of vocalizations, latency to look, and latency to right during a tonic immobility test conducted on progeny from the Controlled Cohort Flocks at 9 weeks of age

\section{Experiment 1}

Variable

$\begin{array}{llllllll}\text { ATI } & \text { V } & \text { LL } & \text { LR } & \text { ATI } & \text { V } & \text { LL } & \text { LR } \\ \# & \# & \text { Latency } & \text { Latency } & & & & \\ \text { Attempts } & \text { Vocalizations } & \text { to Look } & \text { to Right } & & & & \end{array}$

to

Induce

\section{Maternal \\ Age}

\begin{tabular}{lllll} 
Young & $1.77 \pm$ & $2.76 \pm 0.5 b^{\mathrm{ab}}$ & $75.7 \pm$ & $174.4 \pm$ \\
& 0.11 & & 7.47 & 11.78 \\
Ideal & $2.03 \pm$ & \multirow{2}{*}{$3.01 \pm 0.78^{\mathrm{a}}$} & $85.4 \pm$ & $189.0 \pm$ \\
& 0.12 & & 9.46 & 14.33 \\
& & & & \\
Old & $1.66 \pm$ & $2.69 \pm 0.67^{\mathrm{b}}$ & $63.3 \pm$ & $172.1 \pm$ \\
& 0.10 & & 6.01 & 11.4
\end{tabular}

Maternal

Rearing

$=\quad=$ =

X Adult

$\begin{array}{llll}0.7775 & 0.0980 & \overline{0} .0659 & \overline{0} .2490\end{array}$

Housing

\begin{tabular}{|c|c|c|c|c|}
\hline $\begin{array}{l}\text { Trt } 1 \text { (AV } \\
x A V)\end{array}$ & $\begin{array}{l}1.80 \pm \\
0.14\end{array}$ & $2.91 \pm 0.77$ & $\begin{array}{l}65.8 \pm \\
7.86\end{array}$ & $\begin{array}{l}182.8 \pm \\
16.50\end{array}$ \\
\hline $\begin{array}{l}\text { Trt } 2 \text { (CC } \\
x \text { CC) }\end{array}$ & $\begin{array}{l}1.84 \pm \\
0.14\end{array}$ & $3.57 \pm 1.15$ & $\begin{array}{l}85.2 \pm \\
11.65\end{array}$ & $\begin{array}{l}182.8 \pm \\
16.72\end{array}$ \\
\hline $\begin{array}{l}\text { Trt } 3 \text { (AV } \\
\text { x CC) }\end{array}$ & $\begin{array}{l}1.70 \pm \\
0.12\end{array}$ & $3.26 \pm 1.02$ & $\begin{array}{l}63.5 \pm \\
8.41\end{array}$ & $\begin{array}{l}188.1 \pm \\
17.21\end{array}$ \\
\hline $\begin{array}{l}\text { Trt } 4 \text { (CC } \\
\times \text { FC) }\end{array}$ & $\begin{array}{l}1.85 \pm \\
0.14\end{array}$ & $1.78 \pm 0.60$ & $\begin{array}{l}97.8 \pm \\
12.3\end{array}$ & $\begin{array}{l}187.9 \pm \\
15.71\end{array}$ \\
\hline $\begin{array}{l}\text { Trt } 5 \text { (AV } \\
\text { x FC) }\end{array}$ & $\begin{array}{l}1.91 \pm \\
0.15\end{array}$ & $2.52 \pm 0.69$ & $\begin{array}{l}60.44 \pm \\
8.25\end{array}$ & $\begin{array}{l}149.0 \pm \\
14.05\end{array}$ \\
\hline
\end{tabular}

Sex

$\begin{array}{llll}\overline{0} & < & < & = \\ 0.0003 & 0.0001 & 0.0001 & 0.7017\end{array}$

Cockerel $\quad 1.59 \pm$

$0.07^{\mathrm{b}}$

$0.17 \pm 0.05^{b}$

$92.2 \pm$

$7.22^{\mathrm{a}}$

$178.7 \pm$

10.2

Overall $P$-value

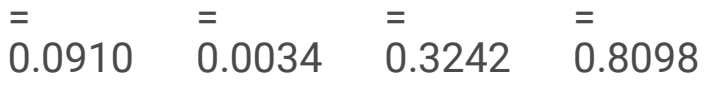




\section{Experiment 1}

\begin{tabular}{|c|c|c|c|c|c|c|c|c|}
\hline Pullet & $\begin{array}{l}2.05 \pm \\
0.10^{a}\end{array}$ & $5.74 \pm 0.77^{a}$ & $\begin{array}{l}54.9 \pm \\
4.52^{b}\end{array}$ & $\begin{array}{l}177.8 \pm \\
10.1\end{array}$ & & & & \\
\hline $\begin{array}{l}\text { Materal } \\
\text { Age x } \\
\text { Sex }\end{array}$ & & & & & $\begin{array}{l}= \\
0.1647\end{array}$ & $\begin{array}{l}< \\
0.0141\end{array}$ & $\begin{array}{l}\overline{=} \\
0.3414\end{array}$ & 0.5522 \\
\hline $\begin{array}{l}\text { Maternal } \\
\text { Age x Trt }\end{array}$ & & & & & $\begin{array}{l}= \\
0.4415\end{array}$ & $\hat{0}_{0.0001}$ & $\begin{array}{l}\overline{=} \\
0.7681\end{array}$ & 0.1832 \\
\hline Trt x Sex & & & & & $\begin{array}{l}\overline{=} \\
0.4981\end{array}$ & $\hat{0}_{0.0001}$ & $\begin{array}{l}= \\
0.1637\end{array}$ & $\begin{array}{l}= \\
0.0171\end{array}$ \\
\hline
\end{tabular}

\section{Discussion}

In the first experiment (E1) of the current study, we observed that aviary-reared hens laid heavier eggs and had offspring that were heavier at hatch, more anxious in the social isolation test and less fearful when subjected to tonic immobility. Housing experience during egg production also affected offspring behaviour, with mothers housed in an aviary producing less anxious offspring. Still in E1, we found that Old hens laid heavier eggs with more yolk percentage, less yolk testosterone and hatched heavier chicks in comparison with Young hens. Behaviourally, the offspring of Old hens were less anxious and fearful. Lastly, a tendency towards Old hens producing less anxious offspring was found in E2, our second experiment that aimed at accessing E1's replicability of maternal age effects in commercial layer breeders.

The importance of rearing environment on physical, behavioural and cognitive development of laying hens has been vastly reported ${ }^{10,43}$. In agreement with previous studies ${ }^{44-47}$, our research shows that rearing environment affects offspring behaviour. In E1, aviary-reared hens had chicks that vocalized more during social isolation and moved quicker out of tonic immobility, indicating higher levels of anxiety but lower fearfulness. As previously reported ${ }^{16}$, the offspring of aviary-reared hens from this same population also showed less displacement preening (an indicator of stress) during a social stress test in comparison with the offspring of cage-reared hens. In addition, E1 showed that aviary-reared hens laid heavier eggs and, consequently, hatched heavier offspring. A recent study of aviary rearing of layer breeder flocks found a sex-dependent effect on offspring hatching weight ${ }^{15}$. Cockerels hatched from breeders reared in aviaries were heavier than those whose mothers were reared in cages - a maternal effect not observed for pullet chicks. However, contrasting results from the literature suggest that other factors, such as genotype and diet, are more likely to affect egg weight than rearing environment ${ }^{48}$. Although the mechanisms and pathways behind the effects of maternal rearing are still largely unknown, research has shown that rearing environment can change the DNA methylation profile of regulatory regions linked with gene expression in 
adult laying hens ${ }^{45}$. Therefore, similarly to other species ${ }^{49}$, epigenetic modifications seem to be the source of maternal effects developed during early life.

The combination between rearing and housing environments increased yolk percentage in Trt 1 (AV x AV) and impaired offspring hatch weight in Trt 2 (CC x CC). Furthermore, contrast analyses showed that offspring from aviary-housed mothers (during egg production) vocalized less during social isolation, indicating less anxiety than the offspring from cage-reared mothers. In agreement with these findings, we previously reported that offspring from mothers housed in aviary systems had lower stress responses (measured as plasma corticosterone concentration) in response to physical restraint ${ }^{16}$. Interestingly, maternal aviary housing caused opposite response of the offspring to social isolation than maternal aviary rearing. This discrepancy confirms the importance of time of stress exposure and suggests that maternal effects are caused by different mechanisms over time. While stressors experienced by the pullet during development might affect her offspring primarily through epigenetics ${ }^{50}$, stress exposure during adulthood seems to lead to changes in concentration of egg yolk hormones, as seen in lizards ${ }^{51}$, quails ${ }^{52,53}$ and laying hens ${ }^{17,54}$. Traditionally, maternally transferred androgens such as testosterone have been suggested as the primary mediator of these effects ${ }^{19}$, but research has also focused on other hormones including glucocorticoids ${ }^{20}$ and thyroid hormones ${ }^{4}$.

Although our analyses of egg composition failed to show an effect of maternal environment on egg yolk testosterone, one of our most significant findings is that the concentration of yolk testosterone progressively decreased as mothers aged, as seen in quails ${ }^{26,27}$. It has been suggested that the natural loss of reproductive function in ageing hens dampers testosterone production by cell layers that surround the growing oocyte ${ }^{5}$. In addition, ageing can influence the embryonic absorption and metabolism of yolk lipids, causing short- and long-term effects on offspring ${ }^{28}$. In E1, both egg weight and offspring hatch weight increased with maternal age, but the offspring of Old mothers displayed the lowest growth rates to 91 days of age and, consequently, the lowest body weight at that same age. Maternal age also affected offspring development in E2, with Ideal mothers producing heavier offspring than Old and Young at 41 days of age. Previous studies have linked the effects of pre-natal testosterone with offspring growth in chickens $^{55}$ and passerine species ${ }^{56}$. Moreover, research on broiler breeders ${ }^{57,58}$ and turkeys ${ }^{59}$ further confirms the effects of maternal age on offspring development.

Regarding the effects of maternal age on offspring behaviour, Old mothers from E1 had chicks that vocalized less during social isolation and showed a shorter latency to approach a novel object, indicating less anxiety and fearfulness in comparison with offspring from Young mothers. Old mothers also showed a tendency to produce less anxious offspring in E2. We previously reported that maternal age affected stress response to physical restraint and injurious social behaviour that was possibly linked to the establishment of a social hierarchy in layers ${ }^{16}$. Although these effects are not yet fully understood, in ovo injections of testosterone were found to affect offspring plasma testosterone concentration and androgen receptor densities within the offspring brain ${ }^{60}$, suggesting a potential pathway for short- and long-term maternal effects. 
Overall, most of the analyzed traits in E1 were not replicated in E2. This might be explained by the genetic differences between laying hens and layer breeders. While we used commercial hens as a model for layer breeders in E1, we directly tested layer breeders in E2. Therefore, results suggest that layer breeders are more resilient to maternal effects than laying hens, as previously reported ${ }^{16,33,35}$. Additionally, our study was performed during an Avian Influenza outbreak across North America that severely limited access to eggs from commercial breeder flocks, thus limiting E2's sample size. As well, commercial breeder flocks are usually fed diets with different nutrient levels over the course of their laying period ${ }^{32}$ (phase feeding) which was not done in our experimental flock in E1. As mentioned previously, maternal nutrition has a significant impact on egg and chick characteristics. Lastly, the housing and social environments of breeder flocks (usually comprising thousands of birds and allowing a natural mating system of hens and roosters ${ }^{32}$ ) can also affect the endocrine status of the hen ${ }^{61}$, thereby affecting the hormone content of the layer breeder's eggs ${ }^{62}$, and potentially masking maternal age effects.

Regardless of maternal environment and maternal age, a sex effect was found in E1 during the social isolation and tonic immobility tests. Sexually dimorphic behaviour is primarily related to the effects of gonadal hormones on the nervous system ${ }^{63}$. Pullets vocalized more than cockerels during the social isolation test at 5 days of age, but this difference depended on age of their mothers. Interestingly, there was no difference between sex when their mothers were Old, when T levels were and TDV were both lowest. In the TI test, pullets needed more attempts to be induced, took less time to look around, and vocalized more than males. These results suggest that female offspring are more anxious but less fearful than males.

Herein, we report that maternal age and maternal environment can affect offspring's development and behaviour when commercial hens are used as a model for breeding chickens. Maternal rearing and housing environment were found to affect anxiety and fearfulness, but in different ways and possibly through different mechanisms. Maternal ageing was shown to decrease the availability of yolk testosterone to the embryo, impair body weight at 91 days of age and decrease anxiety and fearfulness in offspring. A trend to similar effects on offspring behaviour (anxiety levels) were found in layer breeders. Overall, layer breeders seem to be more resilient to the effects of maternal age, but further studies are highly encouraged. In conclusion, we recommend that researchers and producers start noticing and reporting the age and housing condition of their birds' parent stock and encourage farmers to note their flock's parents' age to identify possible behaviour patterns and eventually anticipate productive issues.

\section{Declarations}

\section{Data availability}

The data that support the findings of this study are available from the corresponding author upon reasonable request.

\section{Acknowledgements}


This research was funded by the 2013-2018 Poultry Science Cluster II which was supported by Agriculture and Agri-Food Canada and the Canadian Poultry Research Council, Egg Farmers of Canada and the Ontario Ministry of Agriculture and Rural Affairs (OMAFRA). We thank the personnel at the University of Guelph's Arkell Poultry Research Station for the technical assistance and maintenance of the birds. We also thanks Dr. Alexandra Harlander and Dr. Bas Rodenburg for suggestions during the development of this study.

\section{Contributions}

T.W and L.C. conceived and designed the experiment. L.C. performed the experiment. M.P. and S.H. assisted with data collection. M.P. and T.W. wrote the main manuscript. All authors reviewed and approved the final manuscript.

\section{Correspondence}

Correspondence to Tina Widowski (twidowsk@uoguelph.ca)

\section{Additional information}

\section{Competing interests statement}

The authors declare no competing interests.

\section{References}

1. Cao-Lei, L. et al. Prenatal stress and epigenetics. Neurosci. Biobehav. Rev. (2016). doi:10.1016/j.neubiorev.2017.05.016

2. Frésard, L. et al. Epigenetics and phenotypic variability: Some interesting insights from birds. Genetics Selection Evolution (2013). doi:10.1186/1297-9686-45-16

3. Sepers, B. et al. Avian ecological epigenetics: pitfalls and promises. J. Ornithol.160, 1183-1203 (2019).

4. Groothuis, T. G. G., Hsu, B.-Y., Kumar, N. \& Tschirren, B. Revisiting mechanisms and functions of prenatal hormone-mediated maternal effects using avian species as a model. Philos. Trans. R. Soc. B Biol. Sci.374, 20180115 (2019).

5. Groothuis, T. G. G. \& Schwabl, H. Hormone-mediated maternal effects in birds: Mechanisms matter but what do we know of them? Philos. Trans. R. Soc. B Biol. Sci.363, 1647-1661 (2008).

6. Hy-Line International. Management Guide - HyLine Brown Parent Stock. 44 (2016). Available at: https://www.hyline.com/userdocs/pages/BRN_PS_ENG.pdf. (Accessed: 13th October 2019)

7. Casey-Trott, T. M. et al. Opportunities for exercise during pullet rearing, Part II: Long-term effects on bone characteristics of adult laying hens at the end-of-lay. Poult. Sci.96, 2518-2527 (2017). 
8. Casey-Trott, T. M. et al. Animal well-being and behavior opportunities for exercise during pullet rearing, Part I: Effect on the musculoskeletal characteristics of pullets. Poult. Sci.96, 2509-2517 (2017).

9. Tahamtani, F. M., Nordgreen, J., Nordquist, R. E. \& Janczak, A. M. Early life in a barren environment adversely affects spatial cognition in laying hens (Gallus gallus domesticus). Front. Vet. Sci.2, 1-12 (2015).

10. Janczak, A. M. \& Riber, A. B. Review of rearing-related factors affecting the welfare of laying hens. Poult. Sci.94, 1454-1469 (2015).

11. Brantsæter, M. et al. Exposure to increased environmental complexity during rearing reduces fearfulness and increases use of three-dimensional space in laying hens (Gallus gallus domesticus). Front. Vet. Sci.3,1-10 (2016).

12. Campbell, D. L. M., Hinch, G. N., Downing, J. A. \& Lee, C. Early enrichment in free-range laying hens: effects on ranging behaviour, welfare and response to stressors. Anima/12, 575-584 (2018).

13. Pohle, K. \& Cheng, H.W. Comparative effects of furnished and battery cages on egg production and physiological parameters in White Leghorn hens. Poult. Sci.88, 2042-2051 (2009).

14. Pohle, K. \& Cheng, H.-W. Furnished cage system and hen well-being: Comparative effects of furnished cages and battery cages on behavioral exhibitions in White Leghorn chickens. Poult. Sci.88, 1559-1564 (2009).

15. Damaziak, K., Musielak, M., Musielak, C., Riedel, J. \& Gozdowski, D. Reproductive performance and quality of offsprings of parent stock of layer hens after rearing in open and closed aviary system. Poult. Sci.100, 1120-1131 (2021).

16. Peixoto, M. R. L. V., Cooley, L. \& Widowski, T. M. Maternal age and maternal environment affect stress reactivity and measures of social behaviour in laying hens. Pre-print doi:10.21203/rs.3.rs-420373/v1

17. Bertin, A. et al. Moderate Heat Challenge Increased Yolk Steroid Hormones and Shaped Offspring Growth and Behavior in Chickens. PLoS One8, e57670 (2013).

18. Guibert, F. et al. Trans-generational effects of prenatal stress in quail. Proc. R. Soc. B Biol. Sci.280, 20122368 (2013).

19. Schwabl, H. Yolk is a source of maternal testosterone for developing birds. Proc. Natl. Acad. Sci. U. S. A. (1993). doi:10.1073/pnas.90.24.11446

20. Henriksen, R., Rettenbacher, S. \& Groothuis, T. G. G. Prenatal stress in birds: Pathways, effects, function and perspectives. Neurosci. Biobehav. Rev.35, 1484-1501 (2011).

21. Ruuskanen, S. \& Hsu, B.-Y. Maternal Thyroid Hormones: An Unexplored Mechanism Underlying Maternal Effects in an Ecological Framework. Physiol. Biochem. Zool.91, 904-916 (2018). 
22. Ruuskanen, S., Darras, V. M., Visser, M. E. \& Groothuis, T. G. G. Effects of experimentally manipulated yolk thyroid hormone levels on offspring development in a wild bird species. Horm. Behav.81, 38-44 (2016).

23. Possenti, C. D. et al. Independent and combined effects of egg pro- and anti-oxidants on gull chick phenotype. J. Exp. Biol.221, jeb174300 (2018).

24. Roth, O., Beemelmanns, A., Barribeau, S. M. \& Sadd, B. M. Recent advances in vertebrate and invertebrate transgenerational immunity in the light of ecology and evolution. Heredity (Edinb).121, 225238 (2018).

25. Ahn, D. U., Kim, S. M. \& Shu, H. Effect of Egg Size and Strain and Age of Hens on the Solids Content of Chicken Eggs. Poult. Sci. (1997). doi:10.1093/ps/76.6.914

26. Guibert, F. et al. Yolk testosterone levels and offspring phenotype correlate with parental age in a precocial bird. Physiol. Behav.105, 242-250 (2012).

27. Okuliarová, M., Škrobánek, P. \& Zeman, M. Variability of yolk testosterone concentrations during the reproductive cycle of Japanese quail. Comp. Biochem. Physiol. - A Mol. Integr. Physiol. (2009). doi:10.1016/j.cbpa.2009.08.012

28. Latour, M. A. et al. Broiler Breeder Age and Dietary Fat Influence the Yolk Fatty Acid Profiles of Fresh Eggs and Newly Hatched Chicks. Poult. Sci. (1998). doi:10.1093/ps/77.1.47

29. Burnham, M. R. et al. Effects of incubator humidity and hen age on yolk composition in broiler hatching eggs from young breeders. Poult. Sci. (2001). doi:10.1093/ps/80.10.1444

30. Yilmaz-Dikmen, B. \& Sahan, U. The relationship among age, yolk fatty acids content, and incubation results of broiler breeders. Poult. Sci.88, 185-190 (2009).

31. Nwogu, E. C. \& Acha, C. K. Age of birds at optimal production of eggs: A polynomial regression analysis. Pakistan J. Stat. Oper. Res. (2014). doi:10.18187/pjsor.v10i2.469

32. Hy-Line International. Hy-Line Parent Stock Management Guide. 28

33. Peixoto, M. R. L. V., Karrow, N. A., Newman, A. \& Widowski, T. M. Effects of Maternal Stress on Measures of Anxiety and Fearfulness in Different Strains of Laying Hens. Front. Vet. Sci.7, (2020).

34. Peixoto, M. R. L. V., Karrow, N. A., Newman, A., Head, J. \& Widowski, T. M. Effects of acute stressors experienced by five strains of layer breeders on measures of stress and fear in their offspring. Physiol. Behav.228, 113185 (2021).

35. Peixoto, M. R. L. V., Karrow, N. A. \& Widowski, T. M. Effects of prenatal stress and genetics on embryonic survival and offspring growth of laying hens. Poult. Sci.99, 1618-1627 (2020). 
36. Henriksen, R., Groothuis, T. G. \& Rettenbacher, S. Elevated Plasma Corticosterone Decreases Yolk Testosterone and Progesterone in Chickens: Linking Maternal Stress and Hormone-Mediated Maternal Effects. PLoS One6, e23824 (2011).

37. Sufka, K. J. \& Weed, N. C. Construct validation of behavioral indices of isolation stress and inflammatory nociception in young domestic fowl. Physiol. Behav.55, 741-746 (1994).

38. Sufka, K. J. et al. Modeling the anxiety-depression continuum hypothesis in domestic fowl chicks. Behav. Pharmacol.17, 681-689 (2006).

39. Elliot, A. J. \& Covington, M. V. Approach and Avoidance Motivation. Educ. Psychol. Rev.13, 73-92 (2001).

40. De Haas, E. N., Bolhuis, J. E., Kemp, B., Groothuis, T. G. G. \& Rodenburg, T. B. Parents and early life environment affect behavioral development of laying hen chickens. PLoS One9, 34-38 (2014).

41. Algers, B. et al. Welfare Quality § Assessment protocol for poultry. 111 (2009).

42. Jones, R. B. \& Faure, J. M. Sex and strain comparisons of tonic immobility ("Righting time") in the domestic fowl and the effects of various methods of induction. Behav. Processes6, 47-55 (1981).

43. Campbell, D. L. M., de Haas, E. N. \& Lee, C. A review of environmental enrichment for laying hens during rearing in relation to their behavioral and physiological development. Poult. Sci.98, 9-28 (2019).

44. Goerlich, V. C., Nätt, D., Elfwing, M., Macdonald, B. \& Jensen, P. Transgenerational effects of early experience on behavioral, hormonal and gene expression responses to acute stress in the precocial chicken. Horm. Behav.61, 711-718 (2012).

45. Pértille, F. et al. DNA methylation profiles in red blood cells of adult hens correlate with their rearing conditions. J. Exp. Biol. (2017). doi:10.1242/jeb.157891

46. Pértille, F. et al. Putative Epigenetic Biomarkers of Stress in Red Blood Cells of Chickens Reared Across Different Biomes. Front. Genet.11, (2020).

47. Lindqvist, C. et al. Transmission of stress-induced learning impairment and associated brain gene expression from parents to offspring in chickens. PLoS One2, (2007).

48. Rakonjac, S. et al. Laying hen rearing systems: A review of major production results and egg quality traits. World's Poultry Science Journal70, (2014).

49. Burton, T. \& Metcalfe, N. B. Can environmental conditions experienced in early life influence future generations? Proceedings of the Royal Society B: Biological Sciences281, (2014).

50. Bas Rodenburg, T. \& de Haas, E. N. Of nature and nurture: The role of genetics and environment in behavioural development of laying hens. Current Opinion in Behavioral Sciences7, (2016). 
51. Warner, D. A. \& Lovern, M. B. The maternal environment affects offspring viability via an indirect effect of yolk investment on offspring size. Physiol. Biochem. Zool.87, (2014).

52. Hayward, L. S. \& Wingfield, J. C. Maternal corticosterone is transferred to avian yolk and may alter offspring growth and adult phenotype. Gen. Comp. Endocrinol.135, 365-371 (2004).

53. Guibert, F. et al. Social instability in laying quail: Consequences on yolk steroids and offspring's phenotype. PLoS One (2010). doi:10.1371/journal.pone.0014069

54. Bertin, A. et al. Human behaviour at the origin of maternal effects on offspring behaviour in laying hens (Gallus gallus domesticus). Physiol. Behav.201, 175-183 (2019).

55. Riedstra, B., Pfannkuche, K. A. \& Groothuis, T. G. G. Increased exposure to yolk testosterone has feminizing effects in chickens, Gallus gallus domesticus. Anim. Behav.85, (2013).

56. Ruuskanen, S., Doligez, B., Gustafsson, L. \& Laaksonen, T. Long-term effects of yolk androgens on phenotype and parental feeding behavior in a wild passerine. Behav. Ecol. Sociobiol.66, (2012).

57. Iqbal, J., Khan, S. H., Mukhtar, N., Ahmed, T. \& Pasha, R. A. Effects of egg size (weight) and age on hatching performance and chick quality of broiler breeder. J. Appl. Anim. Res.44, (2016).

58. Peebles, E. D., Zumwalt, C. D., Gerard, P. D., Latour, M. A. \& Smith, T. W. Market age live weight, carcass yield, and liver characteristics of broiler offspring from breeder hens fed diets differing in fat and energy contents. Poult. Sci.81, (2002).

59. Siegel, P. B. et al. Poult performance as influenced by age of dam, genetic line, and dietary vitamin E. Poult. Sci.85, (2006).

60. Pfannkuche, K. A. et al. Examining a pathway for hormone mediated maternal effects - Yolk testosterone affects androgen receptor expression and endogenous testosterone production in young chicks (Gallus gallus domesticus). Gen. Comp. Endocrinol. (2011). doi:10.1016/j.ygcen.2011.04.014

61. Craig, J. V., Craig, J. A. \& Vargas Vargas, J. Corticosteroids and other indicators of hens' well-being in four laying-house environments. Poult. Sci. (1986). doi:10.3382/ps.0650856

62. Groothuis, T. G. G., Müller, W., Von Engelhardt, N., Carere, C. \& Eising, C. Maternal hormones as a tool to adjust offspring phenotype in avian species. Neurosci. Biobehav. Rev.29, 329-352 (2005).

63. Palanza, P. Animal models of anxiety and depression: How are females different? Neurosci. Biobehav. Rev.25, 219-233 (2001).

\section{Figures}




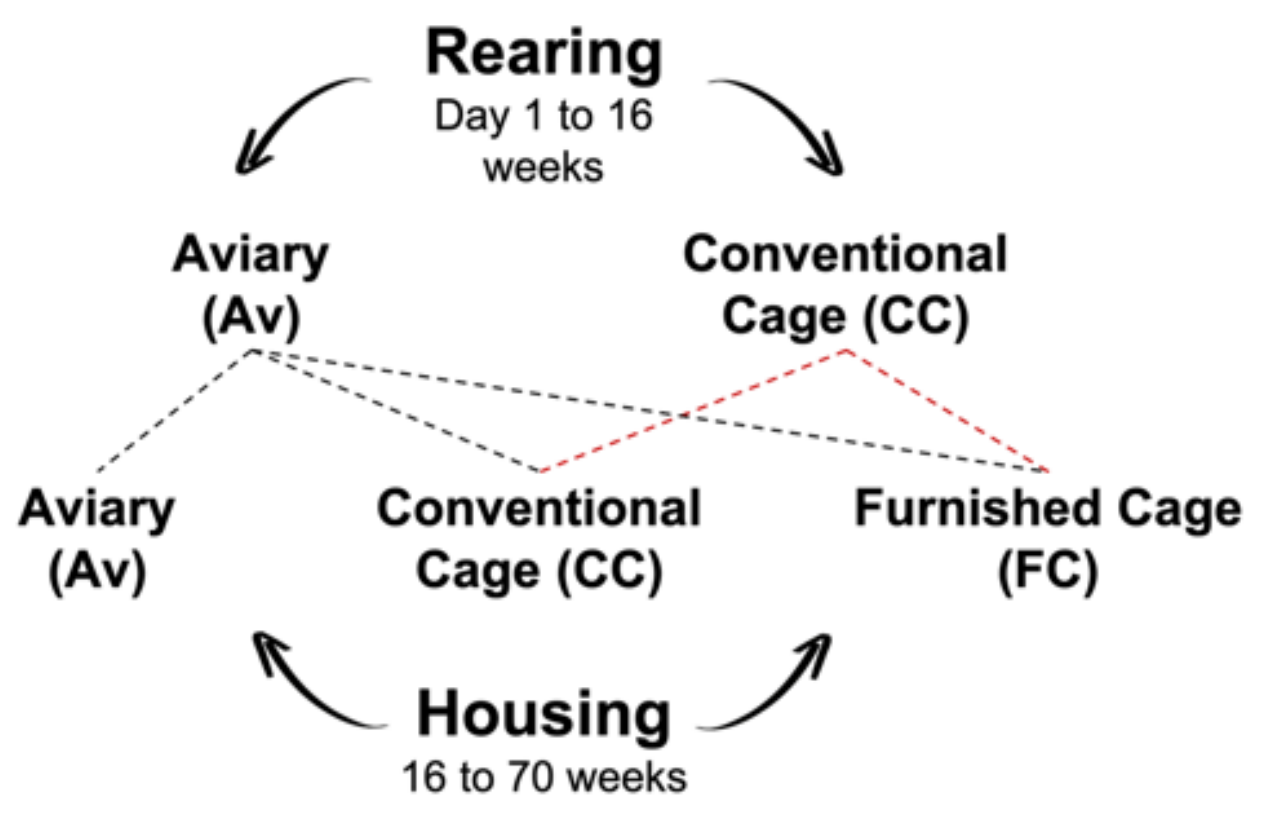

Figure 1

Experiment 1. The combination of maternal rearing and housing experiences formed five treatment groups: Trt1 (Av x Av), Trt2 (CC X CC), Trt3 (Av X CC), Trt4 (CC X FC), Trt5 (Av X FC). This was repeated for two cohorts of hens.

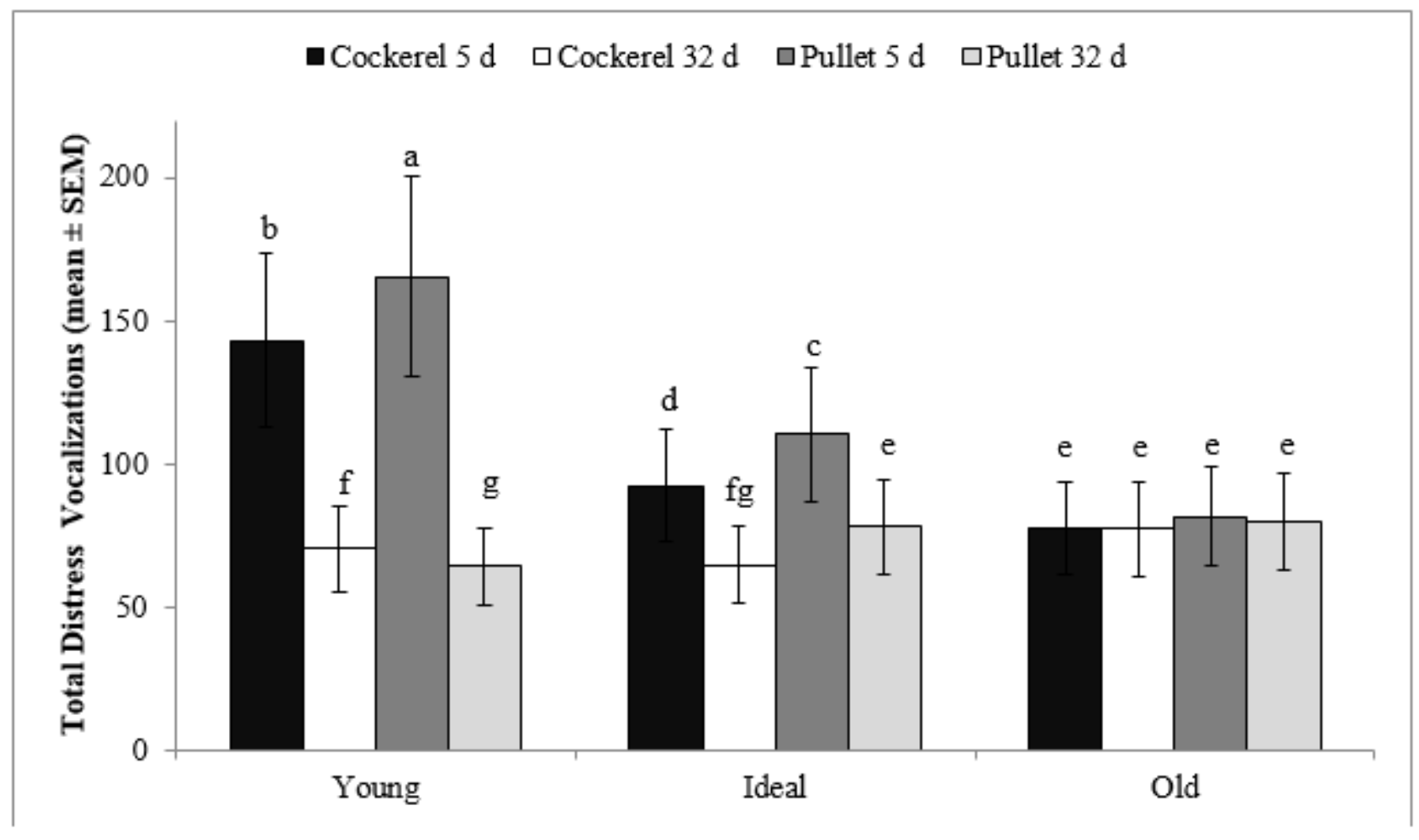

Figure 2 
LSMeans \pm SEM total distress vocalizations (TDV) of 5 day old and 32 day old cockerels and pullets during the 5 -min social isolation test. There was an interaction between maternal age $x$ chick age $x$ sex $(P<0.001)$. Behavioral differences are indicated by different superscripts $(P \leq 0.002) a-g$

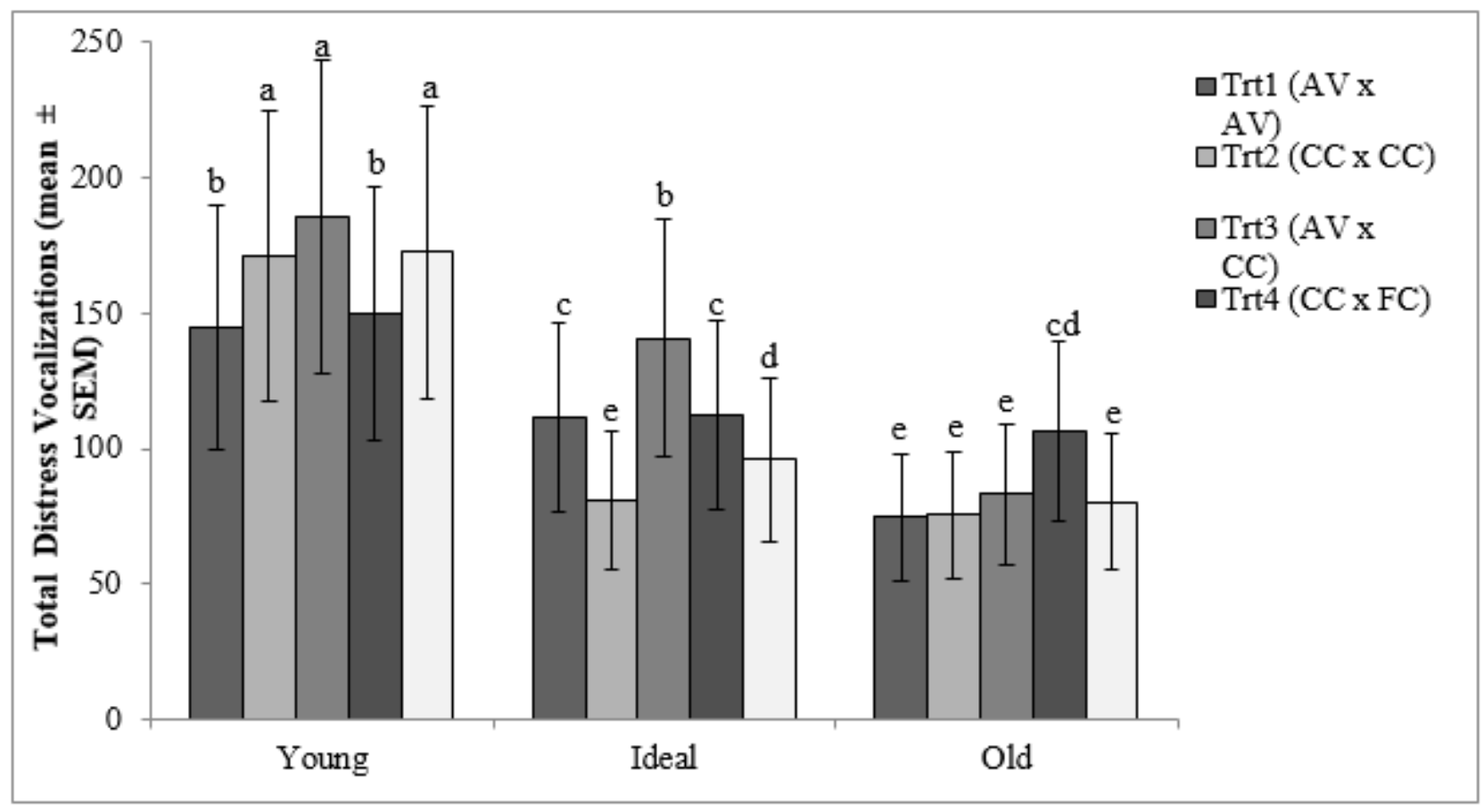

\section{Figure 3}

Social isolation test. LSMean \pm SEM values for total distress vocalizations during 5-min sessions, for Experiment 1 progeny from the different Maternal Rearing $x$ Adult Housing treatments, and from three maternal ages tested at 5 days of age. Behavioral differences are indicated by different superscripts $(\mathrm{P}<0.001 \mathrm{a}-\mathrm{e})$. 